\title{
Weather conditions and Bell's palsy: five-year study and review of the literature \\ Vasilis Danielides ${ }^{* 1}$, George Patrikakos ${ }^{1}$, Christina-Sophia Nousia ${ }^{1}$, Aristides Bartzokas², Haralampos J Milionis3, Christos Lolis4 and Antonios Skevas5
}

Address: ${ }^{1}$ Dept. of Otorhinolaryngology, University of Ioannina, Ioannina, Greece, ${ }^{2}$ Laboratory of Meteorology, Department of Physics, University of Ioannina, Ioannina, Greece, 3Department of Internal Medicine, Medical School, University of Ioannina, Ioannina, Greece, 4Laboratory of Meteorology, Department of Physics, University of Ioannina, Ioannina, Greece and 5Dept. of Otorhinolaryngology, University of Ioannina, Ioannina, Greece

E-mail: Vasilis Danielides* - vdanielidis@ hotmail.com; George Patrikakos - gpatrikakos@ hotmail.com; ChristinaSophia Nousia - bnousias@in.gr; Aristides Bartzokas - abartzok@cc.uoi.gr; Haralampos J Milionis - Hmilioni@cc.uoi.gr; Christos Lolis - meo0061@cc.uoi.gr; Antonios Skevas - otori@cc.uoi.gr

${ }^{*}$ Corresponding author

This article is available from: http://www.biomedcentral.com/I47I-2377/I/7

(C) 200 I Danielides et al; licensee BioMed Central Ltd. Verbatim copying and redistribution of this article are permitted in any medium for any noncommercial purpose, provided this notice is preserved along with the article's original URL. For commercial use, contact info@biomedcentral.com

\begin{abstract}
Background: Climatic or meteorological condition changes have been implicated in the pathogenesis of Bell's palsy (BP). We evaluate the influence of meteorological parameters, such as temperature, humidity, and atmospheric pressure, and their variation and covariation on the incidence of BP and present a review of the literature on the effect of meteorological conditions on facial nerve function.

Methods: A total of 17I cases of BP admitted to our Department over a five-year period were studied. The meteorological database included daily values of 13 distinct parameters recorded at the meteorological station of the University of loannina during this period. A relationship between each meteorological variable and the incidence of $\mathrm{BP}$ was investigated by applying $\left(\mathrm{X}^{2}\right)$ test on data from 13 contingency tables. In addition, the influence of different weather types on the incidence of BP was also investigated. For this purpose Cluster Analysis was used to create eight clusters (weather types) for the loannina prefecture and $\left(\mathrm{X}^{2}\right)$ test was applied on the contingency tables consisting of the days of BP cases for each cluster.
\end{abstract}

Results: No significant correlation was found either between BP and each distinct meteorological parameter or between BP and any specific weather.

Conclusions: Meteorological conditions, such as those dominating in the Northwestern Greece, and/or their changes have little effect on the incidence of BP. Multicenter studies taking into account atmospheric pollution, and climatic differences between countries, are necessary to scrutinize the environmental effects on facial nerve function. 


\section{Background}

Idiopathic peripheral facial nerve paralysis, or Bell's palsy (BP), is the most common cause of facial nerve palsy. BP accounts for approximately $49 \%$ to $51 \%$ of all cases, with an estimated incidence of 13 to 34 cases per 100,000 people per year [1]. A variety of theories have been proposed with regard to its etiology, including viral infection, vascular dysfunction, disorder of the autonomic regulation and inflammation [2].

Climatic or meteorological factors, such as temperature, humidity, or barometric pressure have been implicated in triggering off the pathogenetic mechanism of BP. It has been suggested that a meticulous study of a "combination of changing factors" may help illuminate the underlying pathophysiology of this "puzzling" disease [3]. The seasonal distribution of the disease has been extensively studied [4-14]. However, no consensus has been reached. Patients often recall cooling of the face or a cold draught just before the outburst of the facial palsy. BP following airplane trips has also been reported [3]. Experimental data support a hypothesis of low temperatures in the pathogenesis of BP [15-18].

In the present study, we evaluated the influence of meteorological factors, such as temperature, humidity, and atmospheric pressure, as well as their variation and covariation on the incidence of BP. In addition we have reviewed the literature on the effect of meteorological conditions on facial nerve function.

\section{Materials and methods}

The study was conducted in the prefecture of Ioannina. This part of Northwestern Greece has a population of about 160,000 people. The climate of the area is that of a transient zone (between Mediterranean and Continental). Temperature and relative humidity, during the study period, have ranged between $-9^{\circ} \mathrm{C}$ and $41^{\circ} \mathrm{C}$, and between $7 \%$ and $99 \%$ respectively.

One hundred and seventy-one cases of BP sequentially admitted to our Department over a period of five years (from January 1995 to December 1999) were studied (Figure 1). Subjects with a history of diabetes mellitus, renal, liver, endocrinologic, and neoplastic diseases as well as head injury, post-surgical pareses and ear infections have been excluded from the study. A positive pregnancy test was an additional exclusion criterion [19]. BP day of onset was precisely recorded according to patients' history. Physical examination, auditory tests, and electrophysiologic tests were performed in all patients. Underlying infection was ruled out on the basis of laboratory evaluation, including complete blood count, C-reactive protein, and serological testing for viral disease

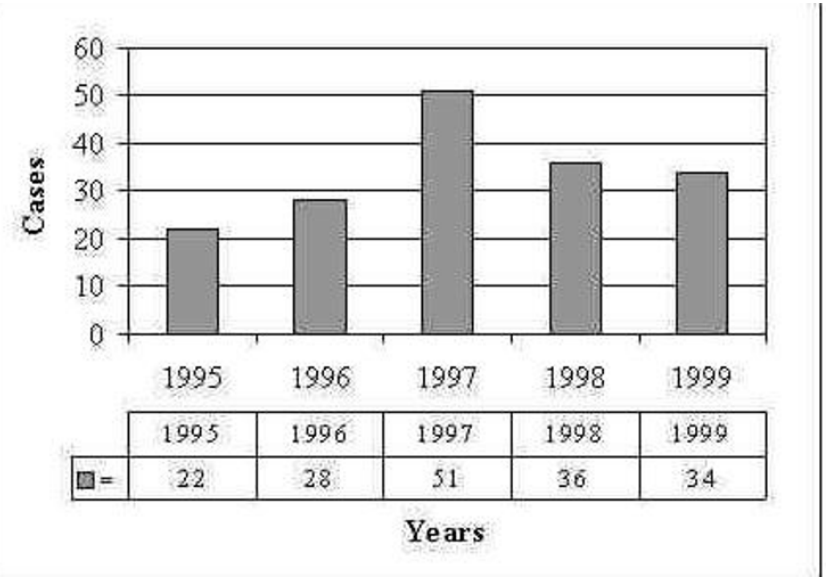

Figure I

Yearly distribution of Bell's palsy cases.

(including hepatitis A, B, C, herpes simplex, HIV, Epstein-Barr, and cytomegalovirus).

The meteorological database included daily values of 13 parameters, recorded at the meteorological station of the University of Ioannina during the study period. The following parameters were recorded:

- Maximum Temperature $\left(\mathrm{T}_{\max }\right)$

- Minimum Temperature $\left(\mathrm{T}_{\min }\right)$

- Mean Temperature (T)

- Diurnal Temperature Range $\left(\mathrm{T}_{\text {range }}=\mathrm{T}_{\max }-\mathrm{T}_{\min }\right)$

- Day to Day Change of Maximum Temperature $\left(\Delta \mathrm{T}_{\max }\right)$

- Day to Day Change of Minimum Temperature $\left(\Delta \mathrm{T}_{\min }\right)$

- Day to Day Change of Mean Temperature $(\Delta \mathrm{T})$

- Mean Atmospheric Pressure reduced to sea level (P)

- Day to Day Change of Mean Atmospheric Pressure ( $\Delta \mathrm{P})$

- Mean Relative Humidity (RH)

- Day to Day Change of Mean Relative Humidity $(\Delta \mathrm{RH})$

- Mean Water Vapor Pressure (e)

- Day to Day Change of Mean Water Vapor Pressure $(\Delta \mathrm{e})$ Water Vapor Pressure (e) was calculated by using Relative Humidity definition (1) and the Clausius- Clapeyron equation (2) as follows: 
(1) $\mathrm{RH}=\mathrm{e} / \mathrm{e}_{\mathrm{s}}$

(2) $\mathrm{de}_{\mathrm{S}} / \mathrm{e}_{\mathrm{S}}=\mathrm{LdT} / \mathrm{R}_{\mathrm{V}} \mathrm{T}^{2}$

where $\mathrm{e}_{\mathrm{S}}$ represents the saturated water vapor pressure, $R_{V}$ the specific gas constant for water vapor and $L$ represents the latent heat of vaporization. Water vapor pressure (e) is another humidity parameter, which is known to be directly related to the amount of water vapor in the atmosphere. A number of researchers used Relative $\mathrm{Hu}-$ midity to evaluate the influence of humidity on human health. However, this is not an appropriate approach, because Relative Humidity reflects the percentage of water saturation in the atmosphere and not the total amount of water vapor. In this respect, a specific amount of water vapor in the atmosphere corresponds to different Relative Humidity levels under different temperatures. Thus, Water Vapor Pressure has to be taken into account primarily.

The relationship between the number of cases of BP and the above meteorological parameters was assessed by using Pearson Chi-square ( $\left.\mathrm{X}^{2}\right)$ test, Factor Analysis (FA), and Cluster Analysis briefly described in the following paragraphs:

(a) The Pearson Chi-square $\left(\mathrm{X}^{2}\right)$ test is the most commonly used procedure for testing independence of row and column classifications in an unordered contingency table.

(b) Factor Analysis (FA) is used in order to reduce the dimensionality of a large data set of $\mathrm{p}$ correlated variables. Each of the $\mathrm{p}$ initial variables $\mathrm{X}_{1}, \mathrm{X}_{2}, \ldots, \mathrm{X}_{\mathrm{p}}$ can be expressed as a linear function of $\mathrm{m}(\mathrm{m}<\mathrm{p})$ uncorrelated factors, i.e. $X_{i}=a_{i 1} F_{1}+a_{i 2} F_{2}+\ldots a_{i m} F_{m}$, where $F_{1}, F_{2}, \ldots$, $\mathrm{F}_{\mathrm{m}}$ are the factors and $\mathrm{a}_{\mathrm{i} 1}, \mathrm{a}_{\mathrm{i} 2}, \ldots \mathrm{a}_{\mathrm{im}}$ are the factor loadings. The values of each factor are called factor scores and they are usually presented standardized, having zero mean and unit variance $[20,21]$. The number $\mathrm{m}$ on the retained factors has to be decided, by using various rules [20-22] and considering the physical interpretation of the results [23].

(c) Cluster analysis (CA) is used in order to classify a series of $\mathrm{n}$ observations into different and characteristic homogenous groups (clusters). Each observation is defined by p variables and it corresponds to one point in the p-dimensional space. Each cluster consists of the points located 'close' to each other. The meaning of 'close' or 'far' between two observations $i$ and $j$ is defined by the square of the Euclidean distance
$D_{i, j}^{2}=\sum_{k=1}^{p}\left(x_{i k}-x_{j k}\right)^{2}$

There are several clustering procedures. Here we used the k-means procedure which, at each step, groups observations into the cluster with the closer center and it recomputes the cluster centers. This process continues until no further changes occur in the centers [24].

In the first part of this work, the values of each meteorological parameter were classified in the 5 quintiles, in a way that the first quintile contains the lowest $20 \%$ and the fifth quintile the highest $20 \%$ of the values. For each quintile, the number of days with $O$ and 1 events of BP were calculated and a contingency table was constructed for each meteorological parameter. There were no days with more than one BP events. The contingency table for maximum temperature is presented as an example. (Table 1)

Table I: Contingency table for Maximum Temperature $\left(T_{\max }\right)$

\begin{tabular}{lll}
\hline Quintiles of $\mathbf{T}_{\max }$ & \multicolumn{2}{c}{ Days } \\
\cline { 2 - 3 } & 0 Events & I Event \\
& & \\
& & 34 \\
$\mathbf{I}\left(\mathrm{T}_{\max }<10.8^{\circ} \mathrm{C}\right)$ & 331 & 35 \\
$\mathbf{2}\left(10.8^{\circ} \mathrm{C}<\mathrm{T}_{\max }<15.4^{\circ} \mathrm{C}\right)$ & 330 & 37 \\
$\mathbf{3}\left(15.4^{\circ} \mathrm{C}<\mathrm{T}_{\max }<22.2^{\circ} \mathrm{C}\right)$ & 328 & 36 \\
$\mathbf{4}\left(22.2^{\circ} \mathrm{C}<\mathrm{T}_{\max }<28.8^{\circ} \mathrm{C}\right)$ & 329 & 29 \\
$\mathbf{5}\left(\mathrm{T}_{\max }>28.8^{\circ} \mathrm{C}\right)$ & 336 & \\
& &
\end{tabular}

For each of the 13 contingency tables Pearson Chi-square $\left(\mathrm{X}^{2}\right)$ test was applied, testing the null hypothesis of independence between the meteorological parameters quintiles and Bell's palsy events. The reason for using contingency tables instead of Pearson correlation is the large divergence of the medical data set from the Gaussian (normal) distribution (many days with zero events).

In the second part of this work, Factor Analysis and Cluster Analysis were used in order to obtain results of the dependence of BP events not on individual meteorological parameters but on the weather in general. At first, FA was applied on the 13 meteorological parameters and led to their reduction to 5 factors, which explain $85 \%$ of Ioannina weather variability. Detailed results of FA are not shown since data reduction is not the main purpose of this work but it is used as an intermediate stage. This re- 


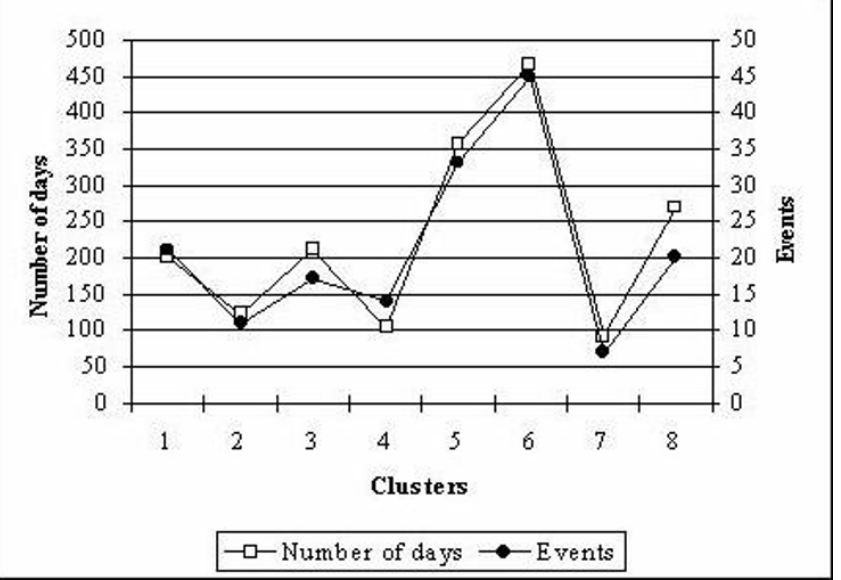

Figure 2

Correlation of variation of number of days and BP events with weather types (clusters).

duction to the main weather components, prior to the application of Cluster Analysis, is considered necessary for higher quality results by many researchers $[25,26]$. Then, Cluster Analysis was applied on the 1826 factor score cases (days) in order to group them objectively into groups of days presenting a characteristic weather type. The dependence of BP events on weather as a whole, was finally tested by applying Chi-square $\left(\mathrm{X}^{2}\right)$ test on a new Contingency table constructed by the Clusters found and the events of BP (O and 1).

\section{Results}

In the first part of the study, we investigated the relationship between meteorological variables and the incidence of BP. The Chi-square $\left(\mathrm{X}^{2}\right)$ test was applied to the 13 contingency tables. There was no statistically significant correlation (Confidence Interval 95\%) between BP events and each of the recorded meteorological parameters.

In the second part of the study, we searched for a relationship between weather types and the incidence of BP. The results of the application of Cluster Analysis on the factor scores time series revealed eight clusters (weather types) for the Ioannina prefecture (Table 2). The mean value of each meteorological parameter recorded from all days of each cluster was calculated so as to provide a realistic overall estimate of the corresponding weather type (Table 3). The frequency of Bell's palsy cases was not found significantly correlated to a specific weather type, at 95\% Confidence level (Figure 2).

In order to obtain a quantitative statistical proof regarding the influence of weather on BP, Chi-square $\left(\mathrm{X}^{2}\right)$ test was applied on a contingency table consisting of the days of Bell's palsy events for each cluster (Table 4). The Chi- square $\left(\mathrm{X}^{2}\right)$ test did not reject the null hypothesis of independence at $95 \%$ confidence level, suggesting that there is not a statistically significant influence of weather on the frequency of BP.

\section{Discussion}

It was as early as the fifth century B.C. when Hippocrates suggested that weather changes might affect physical health $[27,28]$. A relationship between climatic characteristics, such as rain or wind, and chronic disease has been extensively investigated. This association has been demonstrated in patients suffering from rheumatoid arthritis [29], acute gouty arthritis [3O], and SLE, and Behcet's disease [31].

The effect of cold on facial nerve function has been investigated. However, the influence of other atmospheric conditions, such as barometric pressure, humidity or even the covariation of such factors has not been adequately studied. Ding et al conducted an experimental study considering the biologic effects of freezing on the various tissues of the maxillofacial region, including skin, blood vessels, nerves, cartilage and bone. According to their results, a significant immediate paralysis of the facial nerve was evident, which recovered some weeks later [15]. Furthermore, the freezing effect of ice on the facial nerve function was investigated in an attempt to disclose the role of low temperature-induced vasoconstriction of the vasa nervorum in the pathogenesis of BP. In summary, there was not any significant effect on the nerve vessels physiological vasomotor regulation [16]. Hosomi studied the histological alterations following freezing the tympanic part of the facial nerve in mongolian gerbils. Remarkably, $95 \%$ of the specimens exhibited facial palsy. Histological signs of nerve regeneration were obvious at 36 hours and facial nerve function normalized by the $35^{\text {th }}$ day after freezing [17]. By contrast, Zealear et al (1995) did not show any significant effect on facial nerve function following acute and chronic exposure of the tympanic membrane to cold air, in cats and dogs [18].

In a search for the elusive cause of BP, several investigators have endeavored to analyze the influence of weather conditions on the incidence of the disease [4-14]. Most commonly, the possible role of temperature alone in the incidence of the disease attracted interest. In this respect, years were subdivided either as a "four season" pattern or as "warm and cold" periods. This approach is considered highly arbitrary since "seasons" may differ vastly with regard to temperature conditions in subsequent years at the very same location or at different locations. Mair and de Graaf, in 1974, reported the incidence and the epidemiology of BP in sub-arctic Norway during a five-year period. According to their conclusions, there 
Table 2: The main characteristics of the weather type clusters defined for loannina prefecture (1995-99).

\begin{tabular}{|c|c|c|}
\hline & Weather type & \\
\hline Cluster I & Humidity (relative and absolute) decrease & Mostly during the cold period of the year \\
\hline Cluster 2 & Temperature decrease & \\
\hline Cluster 3 & Absolute humidity and minimum temperature decrease & \\
\hline Cluster 4 & Domination of a low pressure system & \\
\hline Cluster 5 & Domination of a high pressure system & \\
\hline Cluster 6 & Persistence of warm and dry weather & Mostly during the warm period of the year \\
\hline Cluster 7 & High temperature, humidity (relative and absolute) increase & \\
\hline Cluster 8 & Humidity (relative and absolute) decrease & \\
\hline
\end{tabular}

Table 3: Mean value of each meteorological parameter in relation to the weather type clusters

\begin{tabular}{|c|c|c|c|c|c|c|c|c|}
\hline \multirow[t]{2}{*}{ Meteorological Parameter } & \multicolumn{8}{|c|}{ Weather types (Clusters) } \\
\hline & $\mathbf{I}$ & 2 & 3 & 4 & 5 & 6 & 7 & 8 \\
\hline $\mathbf{T}_{\max }\left({ }^{\circ} \mathbf{C}\right)$ & 13.6 & 11.9 & 13.1 & 12.7 & 14.3 & 28.7 & 26.2 & 26.6 \\
\hline $\mathbf{T}_{\min }\left({ }^{\circ} \mathbf{C}\right)$ & 4.1 & 4.7 & 6.2 & 6.2 & -0.3 & 11.6 & 15.3 & 13.1 \\
\hline $\mathbf{T}\left({ }^{\circ} \mathbf{C}\right)$ & 8.8 & 8.3 & 9.7 & 9.5 & 7.0 & 20.2 & 20.8 & 19.9 \\
\hline $\mathbf{T}_{\text {range }}\left({ }^{\circ} \mathrm{C}\right)$ & 9.5 & 7.2 & 6.9 & 6.6 & 14.5 & 17.2 & II.I & 13.5 \\
\hline$\Delta \mathbf{T}_{\max }\left({ }^{\circ} \mathbf{C}\right)$ & I.I & -4.1 & 0.0 & -0.2 & 0.6 & 1.2 & -2.7 & -0.9 \\
\hline$\Delta \mathbf{T}_{\min }\left({ }^{\circ} \mathbf{C}\right)$ & 0.0 & -2.1 & 2.8 & 2.8 & -1.5 & -0.1 & 1.7 & -0.7 \\
\hline$\Delta \mathbf{T}\left({ }^{\circ} \mathbf{C}\right)$ & 0.5 & -3.3 & 1.5 & 1.4 & -0.4 & 0.6 & -0.4 & -0.9 \\
\hline$P(\mathbf{h P a})$ & 1012.2 & 1010.8 & 1015.8 & 1007.3 & 1019.1 & 1014.9 & 1013.3 & 1014.0 \\
\hline$\Delta \mathbf{P}$ (hPa) & 0.1 & -0.4 & 2.0 & -6.2 & 0.7 & -0.2 & -0.1 & 0.5 \\
\hline RH (\%) & 61 & 78 & 75 & 80 & 69 & 55 & 73 & 62 \\
\hline$\Delta \mathbf{R H}(\%)$ & -12 & 6 & 0 & 3 & 4 & -1 & 13 & -3 \\
\hline e (hPa) & 7.2 & 8.9 & 9.5 & 9.7 & 7.2 & 13.3 & 18.5 & 14.5 \\
\hline$\Delta \mathrm{e}(\mathrm{hPa})$ & -1.1 & -1.4 & 1.0 & I.I & 0.2 & 0.4 & 2.8 & -1.6 \\
\hline
\end{tabular}

was not any significant difference in the incidence of the disease in Norway, in comparison to that of more temperate regions of the world [32]. Devriese (1977) investigated the relationship between atmospheric pressure and facial nerve palsy in a three-year study period. His statistical analysis, based on recordings of short time pressure changes, changes in two days, and the stability of atmospheric pressure changes within two days, failed to show a positive association between atmospheric pressure changes and the occurrence of BP [3]. In search for a relationship between weather conditions and facial nerve palsy, Herbert et al demonstrated a significant increment in the incidence of the disease on days with low barometric pressure, especially when a low barometric pressure period follows a high one, thus creating great pressure differences [33].
Although the number of the patients was not big enough to extract positive statistical conclusions on the epidemicity and seasonal distribution of Bell's palsy, no such indication was evident. According to the latest literature $[8,14]$, the causative factor of Bell's palsy is the reactivation of Herpes Simplex Virus (HSV) in the ganglion cells. It is proposed to be a reactivation of latent infection and not an acquired one, therefore an epidemic distribution of the disease cannot be expected.

\section{Conclusions}

In the present study, we emphasized on the possible role of weather as the triggering factor of BP. In this respect, we studied a great number of atmospheric parameters using an entirely new statistical methodology. Moreover, we focused on the possible effect that changes of these 
Table 4: Distribution of days with and without Bell's palsy events for each weather type cluster

\begin{tabular}{lcc}
$\begin{array}{l}\text { Weather type } \\
\text { (Cluster) }\end{array}$ & Days & $\begin{array}{c}\text { Frequency (\%) } \\
\text { of BP events }\end{array}$ \\
\cline { 2 - 3 } & 0 (No BP case) $\quad$ I (One BP case) &
\end{tabular}

\begin{tabular}{cccc}
\hline & & & \\
$\mathbf{1}$ & 178 & 21 & $10.6 \%$ \\
$\mathbf{2}$ & 112 & 11 & $8.9 \%$ \\
$\mathbf{3}$ & 192 & 20 & $9.4 \%$ \\
$\mathbf{4}$ & 90 & 14 & $13.5 \%$ \\
$\mathbf{5}$ & 325 & 33 & $9.2 \%$ \\
$\mathbf{6}$ & 423 & 45 & $9.6 \%$ \\
$\mathbf{7}$ & 85 & 7 & $7.6 \%$ \\
$\mathbf{8}$ & 249 & 20 & $7.4 \%$ \\
\hline
\end{tabular}

parameters might have on the incidence of BP over a five-year period.

According to our results, there was no statistically significant correlation between meteorological conditions and the actual incidence of BP. This could be due to the small number of registered cases in our area during the fiveyear study period. Furthermore, an inability to accurately record the day of onset of the disease, based on history taking only, may also provide a limitation. Patients' predisposition about their physical health changes as well as reluctance in seeking medical help for "minor symptoms" could also have an impact.

Future studies involving multicenter reports could be more successful in investigating the influence of environmental factors on facial nerve function. HSV reactivation in association with climatic differences between countries, as well as atmospheric pollution should be also taken into account.

\section{Competing interests}

None declared

\section{Acknowledgements}

This study has been presented at the $2^{\text {nd }}$ World Congress of Otorhinolaryngologic Allergy Endoscopy and Laser Surgery - I Ith Panhellenic Congress of Otorhinolaryngology Head and Neck Surgery, Joint meeting of The American Academy of Otolaryngology - Head and Neck Surgery and of the Panhellenic Society of Otorhinolaryngology), Athens (June 22nd, 200I).

\section{References}

I. Marenda SA, Olsson JE: The evaluation of facial paralysis. In: Rehabilitation of neurotologic diseases. Otolaryngol Clin 1997669-682

2. Zulch KJ: Idiopathic Facial Paralysis. In: Handbook of Clinical Neurology, Diseases of the Nerves Part II (Edited by PJ Vinken and GW Bruyn) New York, North-Holland Publishing Co., Inc; 1970, Chap. 17:24I-302
3. Devriese PP, Fidler V]: Atmospheric Pressure and Idiopathic Facial Paralysis (Bell's Palsy). Aviat Space Environ Med 1977, 48:672-673

4. Adour KK, Winged J: Nonepidemic incidence of idiopathic facial paralysis. Seasonal distribution of 419 cases in three years. JAMA 1974, 227:653-654

5. Adour KK, Byl FM, Hilsinger RL, Kahn ZM, Sheldon MI: The true nature of Bell's palsy: analysis of 1000 consecutive patients. Laryngoscope | 978, 88:787-80|

6. Brandenburg NA, Annegers JF: Incidence and risk factors for Bell's palsy in Larendo, Texas: 1974-1982. Neuroepidemiology 1993, 12:315-325

7. De Almeida MA: Paralisia facial pariférica em Petrópolis. Arq Neuropsiquitatr 1992, 50:60-64

8. De Diego JI, Prim MP, Madero R, Gavillan J: Seasonal patterns of idiopathic facial paralysis: a 16-year study. Otolaryngol Head and Neck Surg 1999, | 20:269-27|

9. Devriese PP, Schumacher T, Scheide A, De Jongh RH, Houtkooper JM: Incidence, prognosis and recovery of Bell's palsy. A survey of about 1000 patients (1974-1983). Clin Otolaryngol Allied Sci 1990, 15:15-27

10. El Ebiary HM: Facial paralysis: A clinical study of $\mathbf{5 8 0}$ cases. Rheumatol Phys Med 197I, II:100-110

1I. Gregg G: Some observations on Bell's palsy in Belfast during the period 1949-1958. Arch Phys Med I 96I, 42:602-608

12. Hauser WA, Karnes WE, Annis J, Kurland LT: Incidence and prognosis of Bell's palsy in the population of Rochester, Minnesota. Mayo Clin Proc 1971, 46:258-264

13. Leibowitz U: Epidemic incidence of Bell's palsy. Brain 1969, 92:109-114

14. Tovi F, Hadar T, Sidi J, Sarov I, Sarov B: Epidemiological aspects of idiopathic peripheral facial paralysis. Eur J Epidemiol 1986, 2:228-232

15. Ding HC, Wang RD, Mao TQ, Peng PQ: Biologic effects of freezing on tissues of the maxillofacial region. J Oral Maxillofac Surg 1985, 43:778-78|

16. Schadel A: Die Auswirkung von Kälte auf die Funktion des Nervus facialis. Laryngo-Rhino-Otol 1990, 69:242-245

17. Hosomi Y: Histopathological study of the recovery process in experimental facial nerve palsy induced by freezing. Nippon Jibiinkoka Gakkai Kaiho 1994, 97:1683-9

18. Zealear DL, Bryant GL Jr, Logan MB, Schwaber MK: An investigation of acute facial paralysis in animals induced by the exposure of the tympanic membrane to cold air. Otolatyngol Head Neck Surg 1995, I 1 3:760-5

19. Danielidis V, Skevas A, Van Kauwenberge P, Vinck B, Tsanades G, Plachouras N: Facial nerve palsy during pregnancy. Acta Otorhinolaryngol Belg 1996, 50:131-135

20. Jolliffe IT: Principal Component Analysis. New York: Springer-Verlag 1986271

21. Manly BFJ: Multivariate Statistical Methods: A Primer. London: Chapman \& Hall 1986159

22. Overland JE, Preisendorfer RW: A Significance Test for Principal Components Applied to a Cyclone Climatology. Mon Weath Rev 1982, I 10: I-4

23. Bartzokas A, Metaxas DA: Covariability and Climatic Changes of the Lower-Troposphere Temperatures over the Northern Hemisphere. II Nuovo Cimento 1993, 16:359-373

24. Sharma S: Applied Multivariate Techniques. John Wiley \& Sons, 1995493

25. McGregor GR, Bamzelis D: Synoptic Typing and its Application tothe Investigation of Weather Air pollution Relationships, Birmingham, United Kingdom. Theor Appl Climatol I 995, 5 I:223236

26. Greene JS, Kalkstein LS, Ye H, Smoyer K: Relationships between Synoptic Climatology and Atmospheric Pollution at 4 US Cities. Theor Appl Climatol 1999, 62:163-174

27. Shutty MS, Cundiff J, DeGood DE: Pain complaint and the weather: weather sensitivity and symptom complaints in chronic pain patients. Pain 1992, 49:199-204

28. Redelmeier DA, Tversky A: On the belief that arthritis pain is related to the weather. Proc Natl Acad Sci USA 1996, 93.2895-2896

29. Jamison RM, Anderson KO, Slater MA: Weather changes and pain: perceived influence of local climate on pain complaint in chronic pain patients. Pain 1995, 61:309-315 
30. Arber N, Vaturi M, Schapiro JM, Jelin N, Weinberger A: Effect of Weather Conditions on Acute Gouty Arthritis. Scand J Rheumatol 1994, 23:22-24

3I. Krause I, Shraga I, Molad Y, Guedj D, Weinberger A: Seasons of the Year and Activity of SLE and Behcet's Disease. Scand J Rheumatol 1997, 26:435-439

32. Mair IWS, DeGraaf AS: Peripheral facial palsy in sub-arctic Norway. Acta Otolaryngol 1974, 77:1 I9- I 25

33. Herbert I, Nolte E, Eicchorn T: Wetterlage und Häufigkeit von idiopathischen Fazialisparesen, Vestibularisausfällen, Ménière-Anfällen und Hörstürzen. Laryng Rhinol Otol 1987, 66:249-250

Publish with BioMed Central and every scientist can read your work free of charge

"BioMedcentral will be the most significant development for disseminating the results of biomedical research in our lifetime."

Paul Nurse, Director-General, Imperial Cancer Research Fund

Publish with BMC and your research papers will be:

- available free of charge to the entire biomedical community

- peer reviewed and published immediately upon acceptance

- cited in PubMed and archived on PubMed Central

- yours - you keep the copyright 